\title{
Mathematical modeling reveals the mechanisms of feedforward regulation in cell fate decisions in budding yeast
}

\author{
Wenlong $\mathrm{Li}^{1}$, Ming $\mathrm{Yi}^{2,3, *}$ and Xiufen $\mathrm{Zou}^{1, *}$ \\ 1 School of Mathematics and Statistics, Wuhan University, Wuhan 430072, China \\ 2 Key Laboratory of Magnetic Resonance in Biological Systems, Wuhan Institute of Physics and Mathematics, Chinese \\ Academy of Sciences, Wuhan 430071, China \\ 3 Department of Physics, College of Science, Huazhong Agricultural University, Wuhan 430070, China \\ * Correspondence: yiming@wipm.ac.cn, xfzou@whu.edu.cn
}

Received January 30, 2015; Revised March 15, 2015; Accepted March 19, 2015

\begin{abstract}
The determination of cell fate is one of the key questions of developmental biology. Recent experiments showed that feedforward regulation is a novel feature of regulatory networks that controls reversible cellular transitions. However, the underlying mechanism of feedforward regulation-mediated cell fate decision is still unclear. Therefore, using experimental data, we develop a full mathematical model of the molecular network responsible for cell fate selection in budding yeast. To validate our theoretical model, we first investigate the dynamical behaviors of key proteins at the Start transition point and the G1/S transition point; a crucial three-node motif consisting of cyclin (CIn1/2), Substrate/Subunit Inhibitor of cyclin-dependent protein kinase (Sic1) and cyclin B (Clb5/6) is considered at these points. The rapid switches of these important components between high and low levels at two transition check points are demonstrated reasonably by our model. Many experimental observations about cell fate decision and cell size control are also theoretically reproduced. Interestingly, the feedforward regulation provides a reliable separation between different cell fates. Next, our model reveals that the threshold for the amount of WHIskey (Whi5) removed from the nucleus is higher at the Reentry point in pheromone-arrested cells compared with that at the Start point in cycling cells. Furthermore, we analyze the hysteresis in the cell cycle kinetics in response to changes in pheromone concentration, showing that $\mathrm{Cln} 3$ is the primary driver of reentry and $\mathrm{C} \ln 1 / 2$ is the secondary driver of reentry. In particular, we demonstrate that the inhibition of Cln1/2 due to the accumulation of Factor ARrest (Far1) directly reinforces arrest. Finally, theoretical work verifies that the three-node coherent feedforward motif created by cell FUSion (Fus3), Far1 and STErile (Ste12) ensures the rapid arrest and reversibility of a cellular state. The combination of our theoretical model and the previous experimental data contributes to the understanding of the molecular mechanisms of the cell fate decision at the G1 phase in budding yeast and will stimulate further biological experiments in future.
\end{abstract}

Keywords: cell fate decision; feedforward mechanism; mathematical modeling; hysteresis; reversibility

\section{INTRODUCTION}

Cells from across biological kingdoms are continuously engaged in the process of decision making. Through decision making, unicellular and multicellular organisms take information from their surroundings (including neighboring cells) and process these data through complex signal transduction and genetic circuits to further modulate cellular phenotypes. Therefore, the selection of cell fate in response to both internal and external stimuli is essential in a cell's life [1]. Much progress in understanding the circuitry underlying decision making, as well as the advantages of the underlying strategic logic implemented therein, has come from budding yeast, the simplest eukaryote [2].

Mathematical modelling is an important method in 
computational and systems biology because it provides the ability to analyze and visualize the complex connections of components in cellular systems. In recent years, the mitogen-activated protein kinase (MAPK) signaling pathway and gene regulatory networks in yeast have been studied extensively and in depth through mathematical modelling and quantitative analysis [3-5].

A previous model of the pheromone pathways [6] proposed an explanation of the graded response of the MATa mating type after stimulation with the pheromone $\alpha$-factor. Due to the lack of G1 cyclins, check point analysis in cell cycle is unable to be developed in this model. In [7], G1 cyclins are taken into account, and a new model for analyzing the cell fate decision mechanism at the Start transition point is constructed. This model explains how the crosstalk between cyclins and signal pathways determines the cell fate decision. Specifically, the function of mutual inhibition between $C \ln 1 / 2$ and Far1 is demonstrated [8,9]. Unfortunately, without $\mathrm{S}$ cyclin proteins, the G1/S transition cannot be analyzed using the model proposed in [7]. A recent research work is focused solely on studying the function of the mutual inhibition between Clb5/6 and Sic 1 at the G1/S transition point [10]. The studies in both [7] and [10] are based on positive feedback regulation. Furthermore, a recent experiment about cellular transitions has shown that the stability of the pheromone-arrested state results from the coherent feedforward regulation of the cell cycle inhibitor Far1 [11,12].

Due to complexity in highly interconnected biochemical networks, many related questions need to be further explored. For example, whether S cycling proteins at G1/ $\mathrm{S}$ transition may interfere with the molecular regulation that allows a single cell to choose between two different fates is still unknown. The exact roles of feedforward regulation in the cell fate decision process are not well established. Moreover, the potential mechanism for rapid arrest and reversibility of cell fate in pheromone-arrested cells is not clear. The feedback-driven hysteresis also remains to be addressed. Thus, it is crucial to thoroughly characterize the features of the cell fate decision network in budding yeast when both motifs associated with the G1/S transition and feedforward regulation are considered.

In this study, we extend these previous models above to present an integrated model that is composed of two subsystems: a G1 phase cell cycle network and a pheromone-induced MAPK pathway. In particular, several important components and regulations, including the transcription regulation of Far1 by Ste12 and the mutual inhibition between Clb5/6 and Substrate/Subunit Inhibitor of cyclin-dependent protein kinase (Sic1), are considered. The cell fate decision occurring at the Start point and the cell size control closely associated with the
G1/S point are both described quantitatively. The underlying mechanism for the different reentry behaviors between pheromone-arrested cells and cycling cells are presented. Finally, the coherent feedforward regulationmediated rapid response and effective separation of cell fate are illustrated. Our work can enrich our understanding of the dynamics and functions of the interaction network that is responsible for selecting between cell cycle commitment and mating arrest.

\section{RESULTS}

\section{Mathematical model}

The aim of our work is to clarify the mechanism underlying the feedforward regulation-mediated cell fate decision when two crucial three-node motifs (i.e., the Cln1/2-Sic1-Clb5/6 motif and the Fus3-Far1-Ste12 motif) are involved. Motivated by some previous works [57,10 ], a full mathematical model is built by combining the schematic diagrams in Figure 1A and Figure 1B. Several assumptions, which are listed below, simplify the model.

- The reactions related to the promotion and inhibition of state transitions, as well as the reactions related to transcriptional regulation, are written using MichaelisMenten kinetics. Meanwhile, phosphorylation reactions are described in terms of mass action laws.

- The stimulus is stable and sufficient when a pheromone signal is required, and the concentrations of $\mathrm{G}_{\alpha \beta \gamma}$, Ste11 and STErile (Ste7) are assumed to be constant.

- For the transcriptional factors SCB binding factor (SBF) and MCB-binding factor (MBF), both of initial concentrations are equal to $100 \mathrm{nM}$, but SBF has a stronger effect than MBF on the promotion of $C \ln 1 / 2$ and Clb5/6. Additional details are presented using the parameters in Table S1 in the Supplementary Materials.

In addition, the detailed network descriptions (Figure S1), which include a subsystem of the cell cycle, a subsystem of the pheromone-induced MAPK pathway and the interactions between the two subsystems, are listed in the Supplementary Materials. The model dynamics are characterized by ordinary differential equations (ODEs), which are presented in the Appendix. The related parameter values and initial concentrations are listed in Table S1 and Table S2 of the Supplementary Materials, respectively, which are mostly acquired from the available literature $[6,7,10]$.

\section{Determination of the Start point in cycling cells}

In yeast, the $\mathrm{G} 1$ checkpoint is vital because it determines whether a cell enters the mitotic cycle or engages in a mating program. Only one fate can be selected from the 


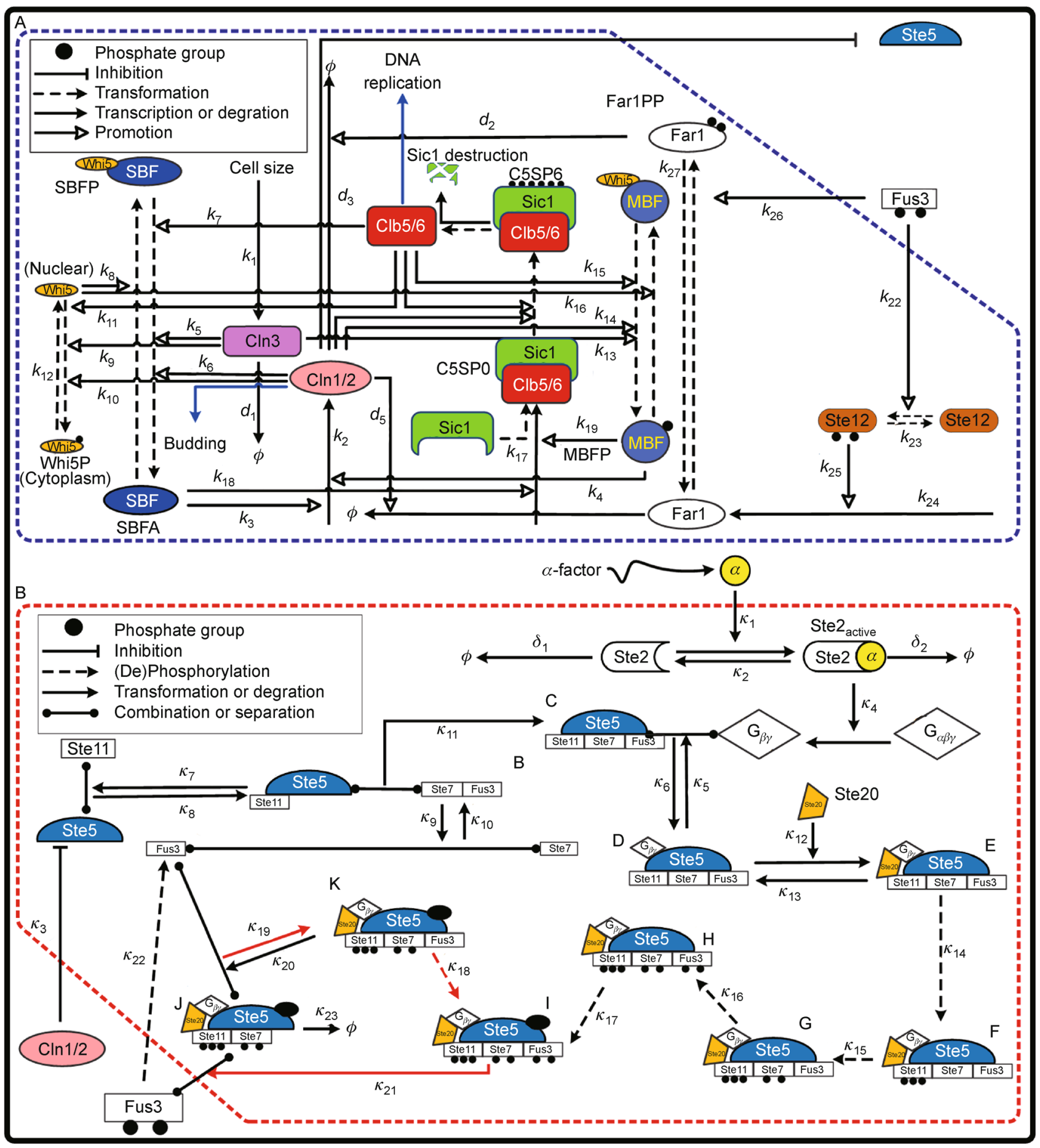

Figure 1. Schematic illustration of two cell network subsystems. All components and reactions considered in our mathematical model are included. All arrows for individual reactions are marked with the corresponding number of this reaction in the model. (A) Cell cycle subsystem of budding yeast in G1 phase. (B) Pheromone-induced MAPK pathway subsystem of budding yeast.

possible two cell fates at the G1 checkpoint. From a system dynamics point of view, the G1 checkpoint is a bistable switch [13-16]. If a cell is not given with any treatment during the next cell cycle at its birth, this type of cell is termed a cycling cell. Moreover, if no special circumstances are noted, the cycling cell is termed a cycling wild-type (WT) cell. The G1 checkpoint of a cycling cell is termed the Start point $[17,18]$. 
Previous studies have identified the fractions of Whi5 protein that are removed from the nucleus as the main indicator for the status of the G1 checkpoint trigger [13]. In the recent work of our group, the Start point is quantified mathematically by the largest derivative in the dose-response curve, which can be obtained from the relationship between the activation of Whi5 (i.e., the proportion of Whi5 that has been exported from the nucleus at $30 \mathrm{~min}$ ) and the pheromone application time [7]. The pheromone application time at the Start point is considered the critical addition time, and the fraction of Whi5 at the Start point is termed the Whi5-threshold.

The critical fractions of Whi5 for cycling cells obtained from the statistical analysis of biological data and the mathematical definition are both approximately equal to $0.5[7,13]$. Therefore, in this study, we still use our original definition [7] to characterize Start point.

\section{Determination of the Reentry point in pheromone-arrested cells}

However, if a cell is pre-exposed to pheromone during the next cell cycle or at birth, it will take longer time to reenter the cell cycle [12]. That is to say, the G1 checkpoint is delayed. In this case, the G1 checkpoint is named a Reentry point [12]. In particular, a cell pre-exposed to $240 \mathrm{nM}$ pheromone for $30 \mathrm{~min}$ is called a pheromonearrested cell. As before, if no special circumstances are noted, a pheromone-arrested cell is termed a pheromonearrested WT cell. The Whi5-threshold is approximately 0.6 for pheromone-arrested cells [12].

To characterize the Reentry point, our original definition is modified by adding pheromone to pheromonearrested cells at $0 \sim 40 \mathrm{~min}$ and measuring the fraction of
Whi5 removed from the nucleus at $50 \mathrm{~min}$ (the preexposed duration is not included). The details are presented below.

\section{Determination of the G1/S transition point}

If a cell passes through the Start point (Reentry point) and enters the cell cycle, the next decision must be made about what time is suitable for entering $\mathrm{S}$ phase and staring DNA replication. The check point between the $\mathrm{G} 1$ and $\mathrm{S}$ phases is defined as the G1/S transition point. If a cell enters $\mathrm{S}$ phase earlier, it will become out of order because the DNA replication-related proteins will be inadequately prepared. However, if a cell enters $\mathrm{S}$ phase later, it will waste resources. Therefore, the decision about the G1/S transition point is critical.

Experimental studies have demonstrated that the G1/S transition point is connected to the cell volume [19-21]. A recent study demonstrated that the switch-like G1/S transition is driven by the degradation of Sicl and that the timing of Sic 1 destruction is set by $\mathrm{Cln} 1 / 2-\mathrm{Cdc} 28$ [10]. Due to the mutual inhibition between $\mathrm{Sic} 1$ and $\mathrm{Clb} 5 / 6$, the level of Sic1 decreases steeply while the level of Clb5/6 increases sharply at the G1/S transition point [10]. It is reasonable to suppose that the crossing point of the two levels is the G1/S transition point in our study (Figure 2A). Moreover, the relationship between the G1/S transition point and the corresponding volume will be analyzed.

\section{Start point and cell fate decision in cycling cells}

Here, the initial states of all cells are assumed to be at the beginning of the G1 phase, and the cells have already

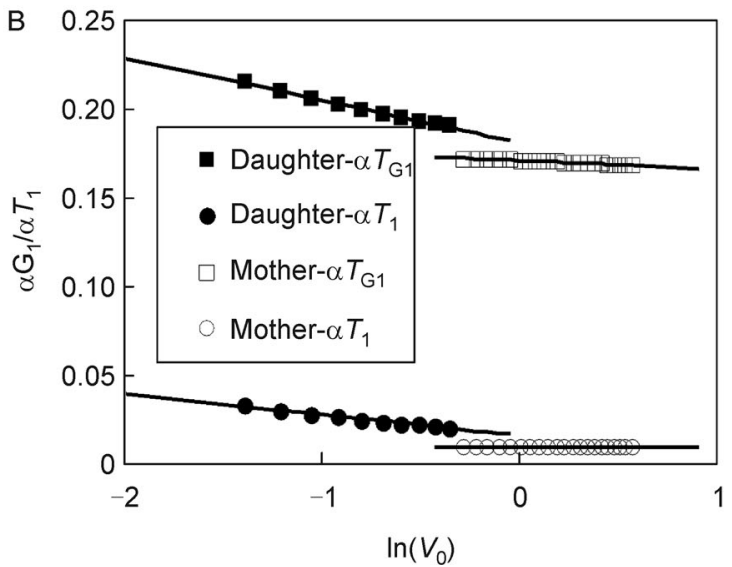

Figure 2. Numerical experiments for cell size control in budding yeast. (A) The definition of the Start point and the G1/S transition point. The Start point occurs when $50 \%$ of Whi5 is removed from the nucleus, and the crossing point of the $\mathrm{Clb} 5 / 6_{\text {free }}$ time course and the Sic1 time course is considered the G1/S transition point. (B) The relationship between the duration of cell cycle and the birth size. 
finished at least one cell cycle. Meanwhile, Cln1/2, SBF and Whi5 are chosen to be the biomarker-like components of cell cycle commitment, and Ste $5_{\text {mem }}$ and Fus3PP are chosen to be the biomarker-like components of mating arrest [22-24].

The addition of $240 \mathrm{nM}$ pheromone to WT cells at various times results in different cell fates, as shown in Figure S2. Apparently, during the competition between the two groups of proteins, once one cell fate dominates, the proteins representing the other cell fate are suppressed completely. These results agree well with experimental data [13].

We further investigate the relationship between the time of pheromone addition and Whi5P activation, as shown in Figure S3. Our calculation for the curve of cell fate decision indicates that there is a sharp transition point at 3 min (i.e., the critical addition time is $3 \mathrm{~min}$.), and the Whi5-threshold is 0.48 . This result is consistent with the experimental observation that the Start point occurs when approximately half of Whi5-GFP $(52 \pm 3 \%)$ has been exported [12,13]. Through a comparison with our previous model [7], here we find that once the fraction of Whi5 removed from the nuclear is beyond the Whi5threshold, nearly all of Whi5 will be exported into the cytoplasm due to a slight increase of the addition time. A potential reason is that our model becomes more exquisite by adding transcription factor MBF and protein $\mathrm{Clb5} / 6$ so that the positive feedback mediated-transport of Whi5 is enhanced largely. Therefore, the Start point is more easily identified in this extended model.

\section{Size control at Start point and G1/S point in cycling cells}

Recent studies have shown that smaller cells have delayed Start transitions, which could imply that a critical size is required to initiate the cell cycle. Namely, if the beginning cell size after the previous division is smaller than a critical size, the cell need to grow to this critical size before entering Start point $[17,19,25,26]$. This feature is called cell size control or a Sizer. However, the period of time from the Start point to the G1/S point is almost fixed and is regarded as a Timer. Cell size control is important and has long been considered to be a main regulator of the length of the G1 phase of the cell cycle, resulting in small difference at cell size after several cycles $[20,26]$. So, it makes sense to clarify this mechanism.

Because asymmetric cell division is a universal mechanism for generating differentiated cells, in budding yeast, asymmetric cell division yields a larger 'mother' cell and a smaller 'daughter' cell. The regulation of gene expression is also asymmetric [25]. Therefore, before we explore the size control of the G1 phase using our model, the mother cell and daughter cell in the beginning of a cell cycle should be defined theoretically. Based on the physiological conditions, for daughter cells, the initial size range varies from $10 \mathrm{fl}$ to $28 \mathrm{fl}$, and the initial $\mathrm{Cln} 3$ concentration is $0 \mathrm{nM}$. Similarly, for mother cells, the initial size range varies from $30 \mathrm{fl}$ to $70 \mathrm{fl}$, and the initial Cln3 concentration is $100 \mathrm{nM}$ [20].

The cell volume is assumed to grow exponentially. Thus, the size at birth $\left(V_{0}\right)$ can be related to the size $(V)$ at an arbitrarily specified time by

$$
\alpha T=\ln (V)-\ln \left(V_{0}\right),
$$

where $\alpha$ is the growth rate of the cell, and $T$ is the growth duration of the cell from birth to the specified time.

Suppose that $T_{1}$ and $T_{\mathrm{G} 1}$ are the durations from birth to the Start point and to the G1/S point, respectively. Meanwhile, $T_{1}$ is considered as the arrest duration (the time from when the pre-exposed pheromone is removed to the Reentry point is also regarded as the arrest duration, namely, $\left.T_{1}\right)$. Moreover, $V_{1}$ and $V_{\mathrm{G} 1}$ are the cell sizes at the Start point and the G1/S point, respectively. For consistency with the bio-experiment, $T_{1}$ and $V_{1}$ are determined by detecting the time point when $50 \%$ of Whi5 removed from the nucleus. $T_{\mathrm{G} 1}$ and $V_{\mathrm{G} 1}$ are derived by recording the crossing points of the Sicl level and the $\mathrm{Clb} 5 / 6_{\text {free }}$ level, respectively. More details are shown in Figure 2A. We can obtain the following equation:

$$
\alpha T_{1}=\ln \left(V_{1}\right)-\ln \left(V_{0}\right) .
$$

We can see from equation (2) that if the Start point is controlled by Sizer, i.e., the cell size $V_{1}$ is a constant, the slope of $\alpha T_{1}$ versus $\ln \left(V_{0}\right)$ will be -1 . By contrast, if the Start point is controlled by Timer, for which $T_{1}$ is fixed, the slope will be $0[19,20]$.

We investigate the relationship between $V_{0}$ and $\alpha T_{1}$ through the growth process of daughter cells and mother cells with different sizes. For the convenience of analysis, we normalize the volume by the mean of the minimum and maximum volumes, that is:

$$
\alpha T_{1}=\ln \left(V_{1} / V_{\text {mean }}\right)-\ln \left(V_{0} / V_{\text {mean }}\right) .
$$

To facilitate observations, we also perform a linear fit to the lifetimes of the mother cells and daughter cells. Lastly, we still use the former symbols to express the normalized values (for example, $V_{0}$ denotes $V_{0} / V_{\text {mean }}$ ). Similarly, we explore the relationship between $V_{0}$ and $\alpha T_{\mathrm{G} 1}$ in the same manner. All results are presented in Figure 2B. The slope of the daughter cells in $T_{1}$ (filled circles) is steeper than the slope of the mother cells in $T_{1}$ (open circles), indicating that mother cells have weaker size control than daughter cells in $T_{1}$. In contrast, we can see that the slope of daughter cells in $T_{1}$ (filled circles) and the slope of daughter cells in $T_{\mathrm{G} 1}$ (filled squares) are almost equal. Similarly, the slope of mother cells in $T_{1}$ (open circles) and the slope of mother cells in $T_{\mathrm{G} 1}$ (open squares) are 
almost equal as well. Therefore, regardless of whether cells are daughter cells or mother cells, the value of $\alpha$ $\left(T_{\mathrm{G} 1}-T_{1}\right)$ roughly is a constant, namely, the duration from the Start point to the G1/S point is almost fixed, so this period is a Timer. These results from our theoretical model agree well with experimental observations [1921]. Moreover, in this simulation, the initial concentration of $C \ln 3$ is set $0 \mathrm{nM}$ and $100 \mathrm{nM}$ in daughter cells and mother cells respectively. And the initial volume which has an impact on the rate of $\mathrm{C} \ln 3$ is perturbed. Therefore, a fact that $\mathrm{G} 1$ cyclin $\mathrm{Cln} 3 \mathrm{had}$ a dominant role in delaying daughters in G1 has been proven with our deterministic method, which had been validated by using statistical methods [20].

\section{Reentry point and cell fate decision in pheromone-arrested cells}

From the recent experiment [12], it has been shown that the Whi5-threshold for pheromone-arrested cells is obviously higher (approximately $0.64 \pm 0.04$ ). However, the biological mechanism is still unclear.

First, the time courses of key proteins under different conditions are plotted (Figures S4 and S5). For pheromone-exposed cells in $0 \mathrm{nM}$ final $\alpha$-factor, our simulation shows that these cells reach the G1/S point in approximately $50 \mathrm{~min}$ (Figure S4A). It is reasonable to check the cellular state at $50 \mathrm{~min}$ for cells whose preexposed duration is less than or equal to $30 \mathrm{~min}$. Therefore, to calculate the Reentry point, we should measure the fraction of Whi5 removed from the nucleus at $50 \mathrm{~min}$. From the time courses of pheromone-exposed cells (Figure S5), we find that if the addition time of pheromone is larger than $21 \mathrm{~min}$, the fate of pheromoneexposed cells is changed from mating arrest into cell cycle.

We also study the relationship between the time of pheromone addition and Whi5P activation (Figure 3 ). The result indicates that the critical addition time is about 21 min. Compared with that of cycling cells in Figure S3, the critical addition time of pheromone-arrested cells is greatly delayed. Moreover, the Whi5-threshold is almost 0.58 , so our theoretical model can predict the experimental value about the Reentry point successfully [12]. This finding suggests that the Whi5-threshold for pheromone-arrested cells is higher than that of cycling cells. Therefore, it is more difficult for pheromonearrested cells to reenter the cell cycle than for cycling cells [12].

\section{Cell hysteresis in a reinforced-arrest model}

The higher Whi5-threshold for pheromone-arrested cells that is noted above suggests that pheromone arrest is

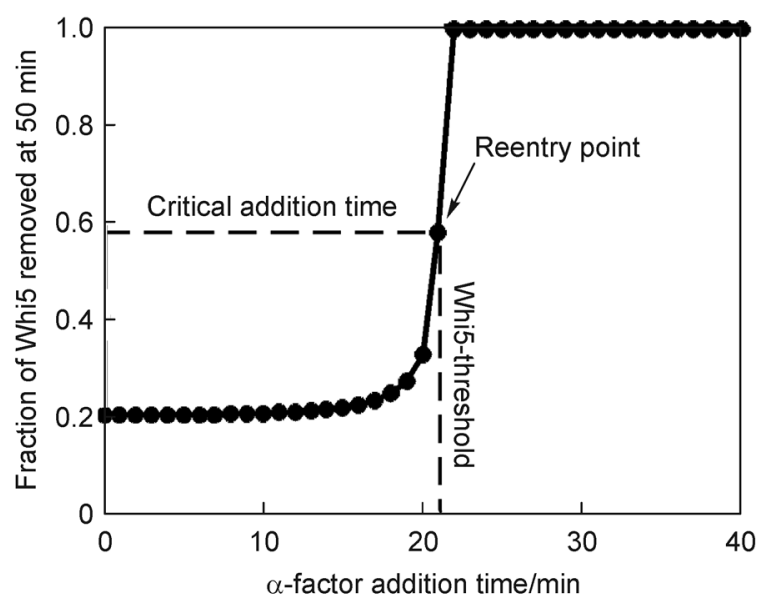

Figure 3. Relationship between the time of pheromone addition and Whi5P activation for pheromonearrested cells. At the Reentry point, the maximum slope is achieved in this curve of cell fate decision. In pheromone-arrested cells, the Reentry point is defined by the export of approximately $58 \%$ of the nuclear Whi5.

reinforced. The reinforcement implies that pheromonearrested cells should exhibit hysteresis kinetics in response to the pheromone concentration compared with cycling cells [12]. To elucidate the relationship between arrest duration and the history of exposure to pheromone, we calculate the arrest duration in the reinforced-arrest model.

We assume that the volumes of cycling cells at $0 \mathrm{~min}$ are set to be the same as the volumes of pheromonearrested cells at $0 \mathrm{~min}$, which have already grown for $30 \mathrm{~min}$ in the growth mode. In addition, to detect the Start point (and Reentry point) and determinate the arrest duration, the Whi5-thresholds of cycling cells and pheromone-arrested cells are set to 0.5 (Figure 2A) and 0.6 (Figure S4), respectively.

The numerical results of the hysteresis experiment are presented in Figure 4A. The arrest durations of these two types of cells in different pheromone concentrations are shown in Figure 4B. The pheromone-arrested cells take much longer to reenter the cell cycle than cycling cells, which are not previously exposed to the high-concentration pulse. This finding shows the hysteresis behavior in pheromone-arrested cells as observed in the experiment [12].

\section{Cycling protein is the main driver of reentry}

We further simulate $\operatorname{con} 1 \Delta \operatorname{col} 2 \Delta$ cells by reducing the generation rate of the $C \ln 1 / 2$ protein to 0.1 times the original rate. The hysteresis experiment is conducted once again for $\operatorname{cln} 1 \Delta \operatorname{cln} 2 \Delta$ cells. The results are shown in 
Figure 4C. The hysteresis phenomenon disappears, suggesting that $\mathrm{Cln} 1$ and $\mathrm{Cln} 2$ are completely inhibited in pheromone-arrested cells [12].

The hysteresis experiment is also simulated for cells lacking the gene $\operatorname{cln} 3$. In $\operatorname{cln} 3 \Delta$ cells, the generation rate of the $C \ln 3$ protein is reduced to 0.25 times the original rate, and the Whi5-threshold is not changed. Figure 4D shows that the arrest duration of $\operatorname{cln} 1 \Delta \operatorname{cln} 2 \Delta$ cells tends to be longer than that of WT cells, whereas the arrest duration of $\operatorname{cln} 3 \Delta$ cells tends to be longer than that of $\operatorname{cln} 1 \Delta \operatorname{con} 2 \Delta$ cells. The cln $3 \Delta$ cells reenter the cell cycle much slowly than do the WT cells and $\operatorname{con} 1 \Delta \operatorname{cln} 2 \Delta$ cells while still showing hysteresis. These results suggest that $\mathrm{Cln} 3$ is the primary driver of reentry and that $\mathrm{C} \ln 1 / 2$ is the secondary driver of reentry.

\section{Pheromone exposure leads to Far1 accumulation}

Reentry into the cell cycle is more difficult for pheromone-arrested cells, and these cells exhibit hysteresis. Moreover, Figure 4C shows that the hysteresis phenomenon in pheromone-arrested model originates

A
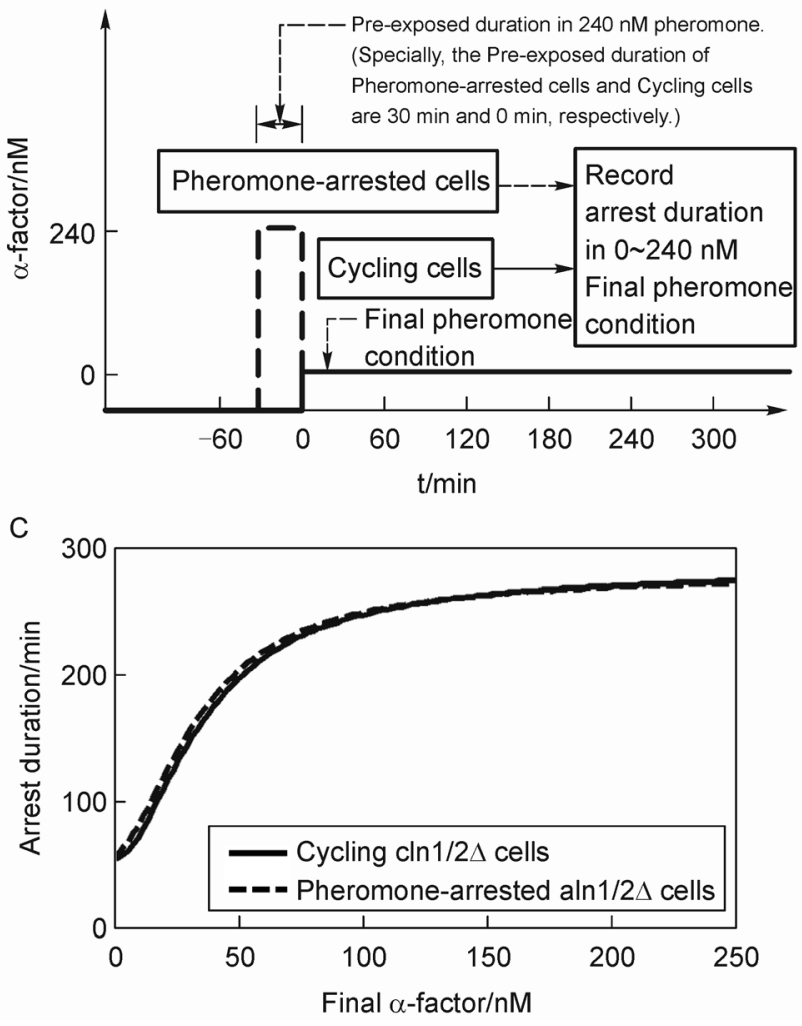

from the inhibition of $C \ln 1 / 2$. As we know, Far1 is the inhibitor of $C \ln 1 / 2$. Thus, it is interesting to investigate whether the accumulation of Far1 is a potential mechanism for arrest reinforcement.

Far1PP (the concentration of phosphorylated Far1) and Far1T (the total concentration of Farl and Far1PP, which is controlled by the transcription factor Ste12) are measured in cells exposed in $240 \mathrm{nM}$ pheromone. Figure 5A shows the time evolutions of the concentrations of Far1PP and Far1T. Our theoretical result clearly demonstrates that Far1T is synthesized slowly, while Far1PP is produced rapidly. Thus, Far1T always accumulates with time when cells are exposed to pheromone. We can predict that pheromone-arrested cells produce more Far1T than that in cycling cells. Therefore, when they are stimulated again, the accumulated Far1T in pheromone-arrested cells will be phosphorylated rapidly into Far1PP, which has higher levels than that in cycling cells. The reentry of pheromone-arrested cells also becomes more difficult compared with that of cycling cells.

To verify our prediction for this feedforward motif of

B

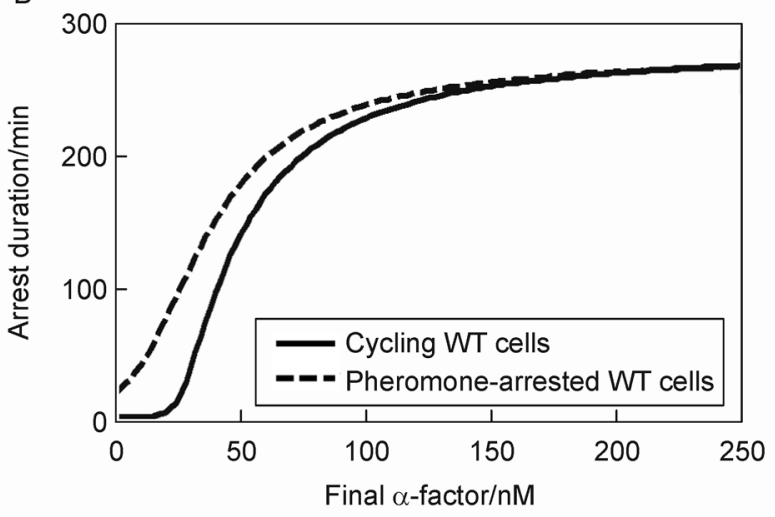

D

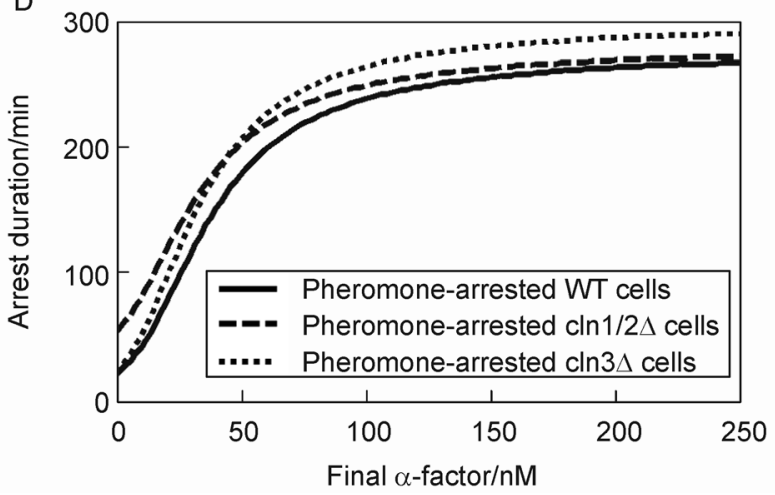

Figure 4. Hysteresis in the cell cycle kinetics in response to changes in pheromone concentration. (A) Schematic of the hysteresis experiment. Experimental group cells are exposed to $240 \mathrm{nM}$ a-factor for $30 \mathrm{~min}$ (pheromone-arrested cells), and control group cells are not treated with anything (cycling cells). Then, the two groups of cells are exposed to different $\alpha$-factor concentrations (different conditions). (B) Duration of arrest in pheromone-arrested cells and cycling cells in different conditions. (C) Hysteresis experiment for cells lacking the gene $\operatorname{cln} 1 / 2$. (D) Arrest duration of pheromone-arrested cells lacking the gene cln $1 / 2$, pheromonearrested cells lacking the gene cln3 and pheromone-arrested WT cells in different conditions. 

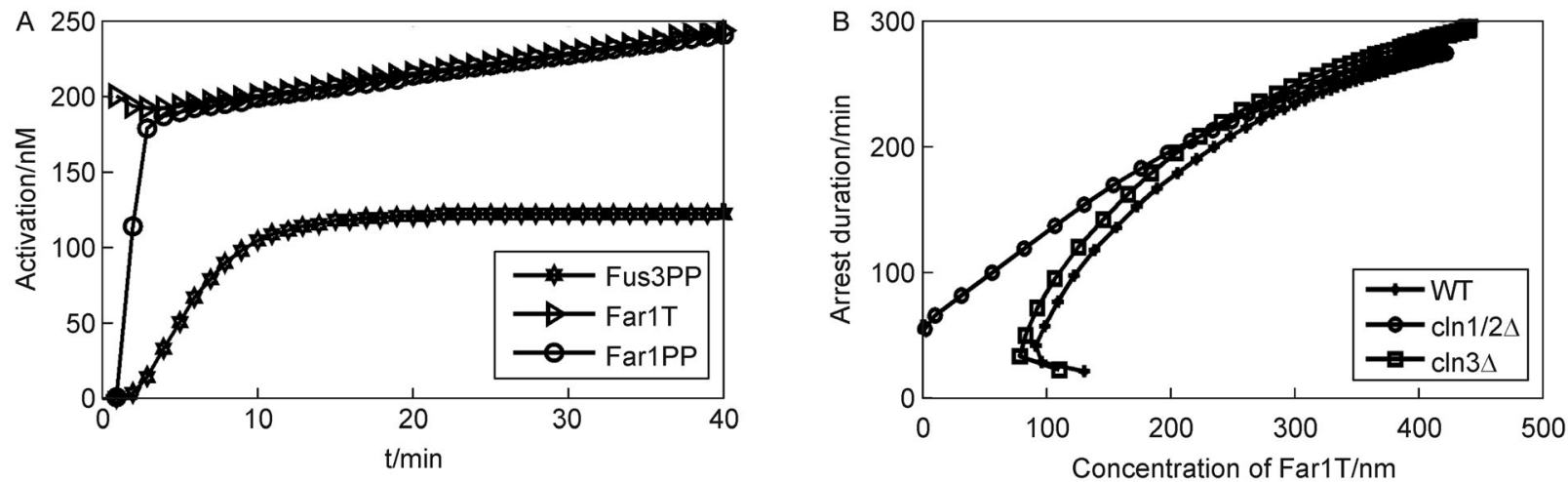

Figure 5. Dynamical analysis for the feedforward motif with slow transcription and fast phosphorylation. (A) Time courses of Fus3PP, synthesized Far1 (i.e., Far1T) and phosphorylated Far1 (i.e., Far1PP) in WT cells pre-exposed to 240 nM pheromone. (B) Phase diagram of the arrest duration and the Far1T abundance at the Reentry point for WT cells, cln $1 / 2 \Delta$ cells, and cln $3 \Delta$ cells for changes in the final pheromone concentration in the hysteresis experiment.

Fus3-Far1-Ste12, different types of pheromone-arrested cells (including pheromone-arrested WT cells, pheromone-arrested $\operatorname{cln} 1 / 2 \Delta$ cells, and pheromone-arrested $\operatorname{cln} 3 \Delta$ cells) are exposed to different final concentrations of pheromone from $0 \mathrm{nM}$ to $240 \mathrm{nM}$. Then, we analyzed the relationships between the concentration of Far1T and the arrest duration for those cells at Reentry point. As shown in Figure 5B, our result implies that Far1 accumulation and the arrest duration at the Reentry point are almost positively correlated. Therefore, the arrest reinforcement potentially results from the accumulation of Far1.

\section{Accumulated CDK inhibitor increases Whi5-threshold}

In the experiment, the final concentration in the pheromone pulse is adjustable, whereas the duration of pre-exposure is fixed $(30 \mathrm{~min})$. Therefore, we further explore theoretically the effects of different pre-exposed durations on the Reentry point. By varying the preexposed duration $(240 \mathrm{nM})$ from 0 min to $30 \mathrm{~min}$ and setting the final pheromone concentration to $0 \mathrm{nM}$, we record the Whi5-threshold using the method of threshold determination for pheromone-arrested cells presented above.

In Figure 6A, the variations in the Whi5-threshold for different pre-exposed durations are derived. As shown in insets of Figure 6A, the Whi5-thresholds are taken from the critical points in the curves of cell fate decision. The Whi5-threshold appears to increase. This finding is obvious and expected because pheromone-activated Fus3 inhibits the cycling protein via Far1, and it will become very difficult for Cln-CDK to occupy the dominant position when the amount of the inhibitor
Farl increases. Therefore, the cell transition from arrest to the cell cycle requires a higher threshold.

The arrest duration and critical addition time in different conditions are given in Figure 6B. Both the arrest duration and the critical addition time increase first and then reach the saturation values when the duration of the pheromone pulse is longer than approximately 4.5 min. By comparing the two lines, we discover that they almost coincide. This overlap is inevitable because the transition of Whi5 at the critical addition time of pheromone (i.e., Whi5-threshold) is very sharp. Thus, the cell states are divided into two different fates by this critical addition time point (Figure S5C), and this time point is almost the same as the Reentry point (Figure $\mathrm{S} 4 \mathrm{~A})$. Therefore, this result confirms that this time is really Reentry point.

Furthermore, we find that longer pheromone exposure makes cells more reluctantly commit to cell cycle reentry (i.e., longer arrest duration). This feature may be a robust design in biology because the larger threshold and longer arrest duration enhance the chance of mating with other partners.

\section{Alternative Far1 regulatory mechanisms are deficient}

Why has the fate decision system in budding yeast evolved into a coherent feedforward regulatory mechanism? To reveal the advantage of the Fus3-Far1-Ste12 feedforward motif, several alternative Farl regulatory mechanisms are selected for slight adjustments. We compare three types of regulatory structures with the feedforward motif, including a positive feedback motif (PF motif), a transcription only motif (TO motif), a phosphorylation only motif (PO motif). Each motif is 

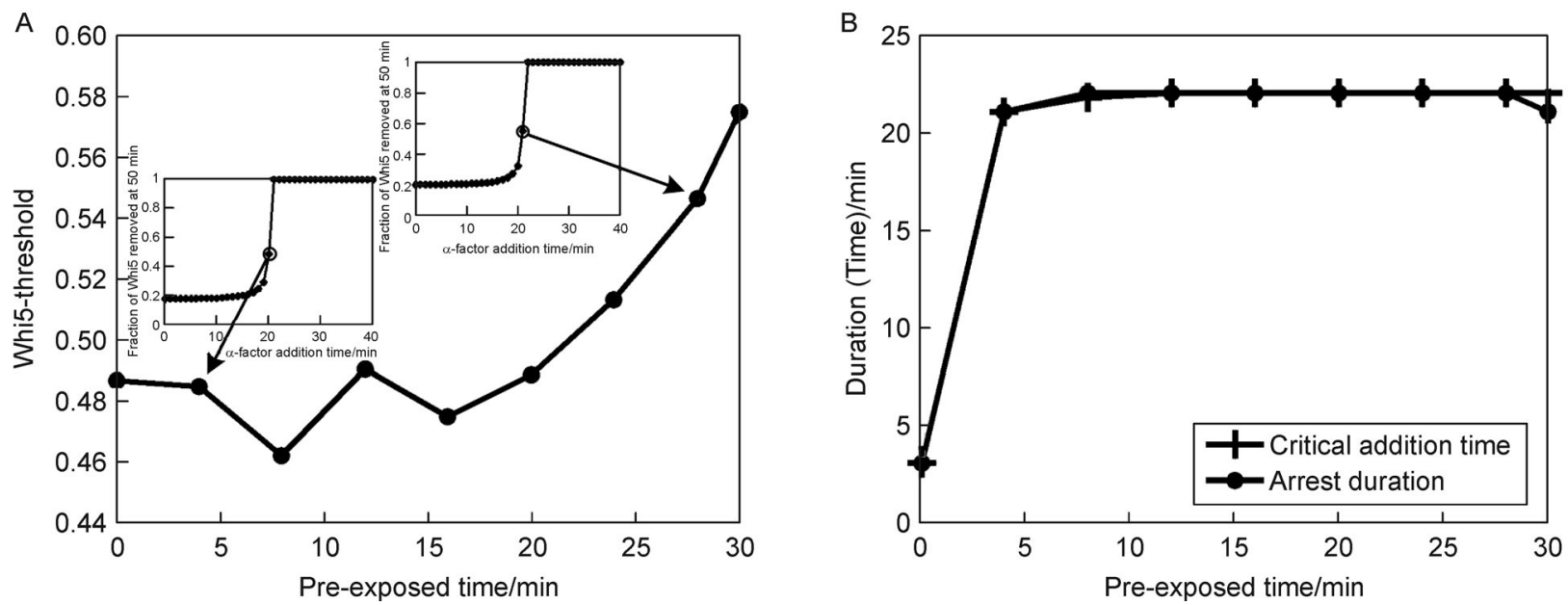

Figure 6. Whi5-threshold and arrest duration are enhanced by increases in the pre-exposed duration. (A) The relationship between the pre-exposed duration and Whi5-threshold. (B) The relationship of the arrest duration and the critical addition time with pre-exposed duration.

embedded in the original networks. Then, the related equations are changed.

For the PF motif, equations B1 and B2 are changed into the following two equations:

$$
\begin{aligned}
\frac{\mathrm{d}}{\mathrm{d} t}[\text { Ste2 }]= & -\kappa_{1}[\text { Ste } 2]\left(\left(0.1+\frac{k k_{1}[F u s 3 P P]^{n}}{k k_{2}+[F u s 3 P P]^{n}}\right)\right. \\
& \left.+\left(0.1+\frac{k k_{3}[\text { Ste } 12 P P]^{n}}{k k_{4}+[S t e 12 P P]^{n}}\right)\right) \alpha(t) \\
& +\kappa_{2}\left[\text { Ste } 2_{\text {active }}\right]-\delta_{1}\left[S t e 2_{\text {active }}\right], \\
\frac{\mathrm{d}}{\mathrm{d} t}\left[\text { Ste } 2_{\text {active }}\right]= & \kappa_{1}[\text { Ste } 2]\left(\left(0.1+\frac{k k_{1}[\text { Fus } 3 P P]^{n}}{k k_{2}+[F u s 3 P P]^{n}}\right)\right. \\
& \left.+\left(0.1+\frac{k k_{3}[\text { Ste } 12 P P]^{n}}{k k_{4}+[\text { Ste } 12 P P]^{n}}\right)\right) \alpha(t) \\
& -\kappa_{2}\left[\text { Ste } 2_{\text {active }}\right]-\delta_{2}\left[S t e 2_{\text {active }}\right] .
\end{aligned}
$$

For the TO motif, we assume that all Far1 produced is active and that all regulation is governed by production, degradation and dilution. Equation A30 is removed, and equations A3 and A29 are modified into the following two equations:

$$
\begin{aligned}
\frac{\mathrm{d}}{\mathrm{d} t}[C \ln 1 / 2]= & k_{2}+\frac{k_{3}[S B F A]+k_{4}[M B F P]}{1+K_{3}[S B F A]+K_{4}[M B F P]} \\
& -d_{2}[\operatorname{Far} 1][C \ln 1 / 2]-d_{3}[C \ln 1 / 2],
\end{aligned}
$$

$$
\begin{aligned}
\frac{\mathrm{d}}{\mathrm{d} t}[\text { Far } 1]= & k_{24}+k_{25}[\text { Ste } 12 P P]-d_{5}[\text { Cln } 1 / 2][\text { Far } 1] \\
& -d_{9}[\text { Far } 1] .
\end{aligned}
$$

For the PO motif, we suppose that the total dosage of Far1 is equal to $200 \mathrm{nM}$. Equation A29 is changed as below:

$$
\frac{\mathrm{d}}{\mathrm{d} t}[\text { Far } 1]=0
$$

All reaction motifs and their kinetic properties are organized in Figure 7A. In Figure 7B, the time courses of $\mathrm{Cln} 3$ and $\mathrm{Far} 1_{\text {act }}$ are exhibited for the addition of $\alpha$-factor at $2 \mathrm{~min}$ and the removal after $4 \mathrm{~min}$. For the TO motif (Figure 7B3), a relatively slow increase in Farl $1_{\text {act }}$ is observed when $\alpha$-factor is added, and the level of Far $1_{\text {act }}$ is also decreased slowly when $\alpha$-factor is removed. This result suggests that the TO structure cannot trigger rapid arrest and rapid reversibility. However, other motifs perform this function normally.

Moreover, the dependence of MAPK activity (which is measured via the concentration of Fus3PP) on $\alpha$-factor for different conditions is also investigated by bifurcation analysis. The results are presented in Figure 7C. Comparisons reveal that the degree of MAPK activity cannot be derived when the concentration of $\alpha$-factor ranges from $25 \mathrm{nM}$ to $30 \mathrm{nM}$ for the $\mathrm{PF}$ motif (Figure 7C2). The positive feedback creates a bi-stable response for this range of $\alpha$-factor, leading to the loss of information. However, the MAPK pathway activity is linear over a broad range of extracellular pheromone concentrations, similar to its behavior for other motifs [24,27-29]. Hence, our result indicates that reversible positive feedback cannot monotonously encode extracellular information.

Next, we study the cell fate decision of pheromonearrested cells with Reentry point. The results are shown in 
Wenlong Li et al.

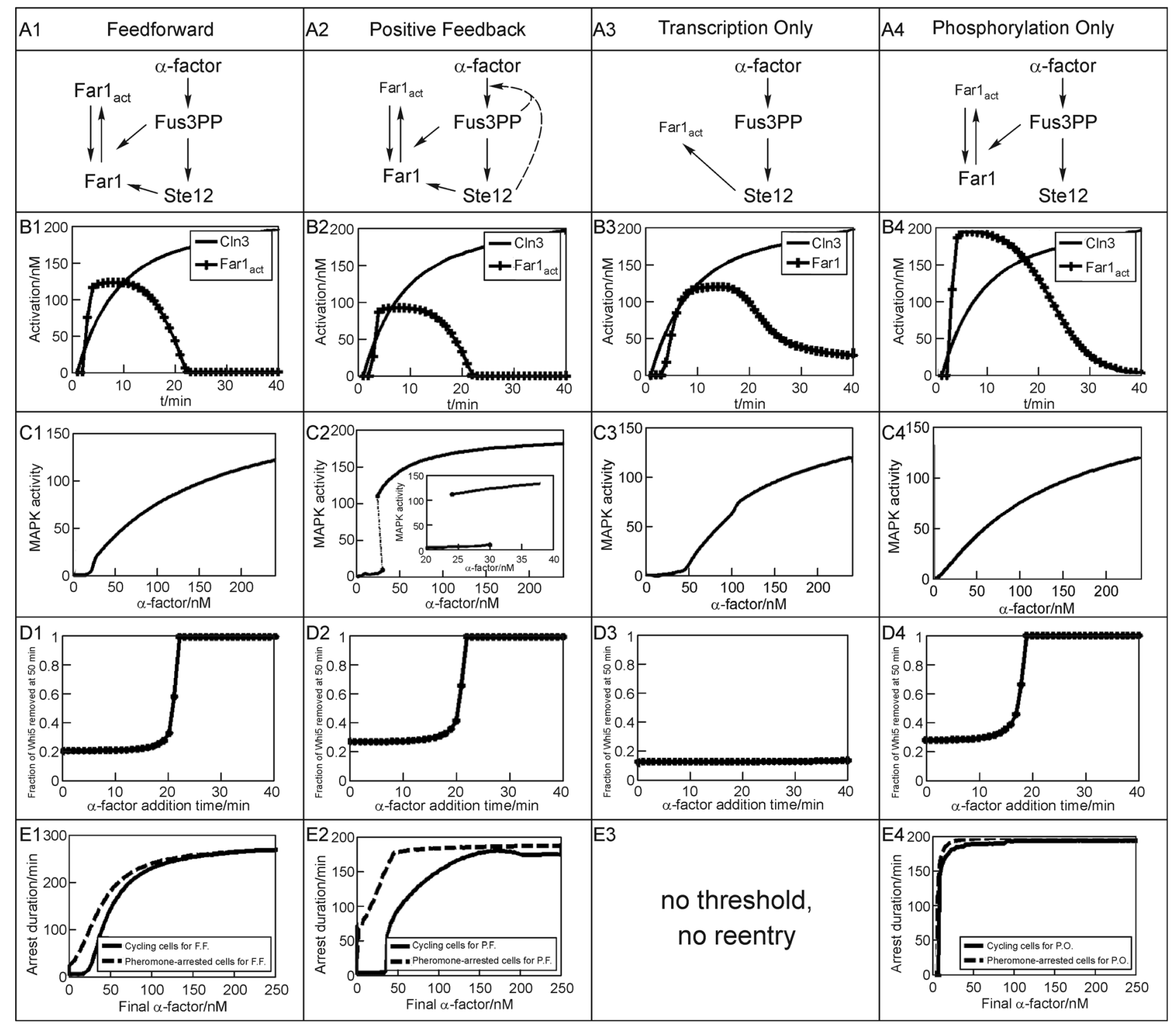

Figure 7. Comparison between the feedforward motif and other structures. (A) Here, we consider four categories of networks that control the level of active Far1. (B) A general response for the networks to a square pulse of the mating pheromone. (C) The steady state relationship between MAPK activity and the mating pheromone. (D) Relationship between the time of pheromone addition and Whi5P activation. (E) Hysteresis experiment for different Far1 regulatory mechanisms. Only the feedforward regulation fulfills all requirements (rapid activation and reentry, ability to continually sense extracellular information, reliable separation of cell fates, and hysteresis effect).

Figure 7D. From these curves of fate decision, we find that there is not a Whi5-threshold for the TO motif (Figure 7D3). Further, we suppose there is a longer time for the G1 check point and the G1/S point for the TO motif, which thus extends the range of addition time. However, the Whi5-threshold is still undetected. This finding implies that the TO motif does not have a reentry threshold. In detail, the cell state would always be in mating arrest regardless of when $\alpha$-factor is added due to the loss of fate decision ability. This is a fatal design because it will lead to confusion in the biological regulation. However, other motifs have clear Reentry points.

Finally, the hysteresis experiment is conducted theoretically. The results for each of the different motifs are indicated in Figure 7E. The hysteresis effect of the PO motif is not evident (Figure 7E4), which means that for the PO motif, the memory of its history is not very strong. Moreover, this result proves that hysteresis behavior is resulted exactly from the accumulation of Far1. Further- 
more, for the TO motif, there is no hysteresis curve due to the lack of a Reentry point (Figure 7E3).

By comparing the properties of all motifs, we easily find that the feedforward motif is the best design because it excels in the functions we have listed, whereas the other motifs do not. For example, the PF motif cannot encode external information monotonously, the TO motif lacks the functions of rapid arrest and rapid reversibility, and the PO motif cannot produce the hysteresis.

\section{DISCUSSION AND CONCLUSION}

The decision of the budding yeast between cell cycle commitment and mating arrest involves a complex process, including translocation of Whi5 between the cytoplasm and the nucleus, recruitment of the scaffold protein Ste 5 , multisite phosphorylation of Ste 5 by $C \ln 1 / 2$, mutual inhibition between $C \ln 1 / 2$ and Far1, a series of transitions between the active and inactive states of kinase proteins, and so forth.

However, two important regulatory motifs were neglected in the previous models of cell fate decision. The first motif is the Cln1/2-Sic1- Clb5/6 motif, which is tightly associated with the G1/S transition in cell cycle subsystem. The potential roles of a double negative feedback loop between $\mathrm{Clb5} / 6$ and Sic1 and the inhibition of $\mathrm{C} \ln 1 / 2$ by $\mathrm{Sic} 1$ in the maintenance and selection of different cell fates are still poorly understood. The second motif is the coherent feedforward loop created by Fus3Far1-Ste12 in the MAPK pathway subsystem. Although the key functions of the feedforward loop in the cellular transition of pheromone-arrested cells have been investigated experimentally, the relationship between the structure of these motifs and dynamical features of the cell fate decision remains unresolved.

To identify the mechanisms underlying the cell fate decisions for cycling cells and pheromone-arrested cells, in this study, we construct a full mathematical model of the regulatory network for cell fate decision in the G1 phase of budding yeast. Specially, the Cln1/2-Sic1-Clb5/6 motif and the Fus3-Far1-Ste12 motif are taken into account. We find that the involvement of these two motifs in the cell fate decision network ensures the effective separation and flexible transition between different cell fates.

First, the Start point and the G1/S point in cycling cells are quantitatively reproduced. It is obvious that the Start point can be identified more easily in the present model than in our original model [7]. The alternating switching of key proteins between high and low levels are observed. Some reasonable observations for cell size control also emerge from our numerical experiments. Because the Cln1/2-Sic1-Clb5/6 motif can only be activated after the Start point in the simulation, we believe the Fus3-Far1-
Ste12 motif provides the improvement in our model's performance. This finding implies that feedforward regulation ensures the reliable separation of different cell fates.

Second, the Reentry point in pheromone-arrested cells is studied. The threshold for reentry in pheromonearrested cells is exactly higher than the corresponding threshold for cycling cells. Moreover, the hysteresis behavior in cell cycle kinetics in response to changes in pheromone concentration is reproduced theoretically using our model [12]. We deduce that $\operatorname{Cln} 3$ is the primary driver of reentry and that the accumulation of Far1 directly reinforces arrest.

Finally, we confirm that Far1 accumulates slowly to ensure stability against size-dependent increases in $\mathrm{Cln} 3$ activity [21], because the small fluctuation of $C \ln 3$ level can be filtered due to the increase of CDK-threshold. Whereas fast phosphorylation cycles of Far1 allow rapid responses including rapid activation and reentry. Our results have shed light on the physiological functions of feedforward regulation and promoted our understanding of the molecular mechanisms of feedforward regulationmediated cell fate decision in budding yeast.

Due to the complexity of the cell fate selection network, further work to refine our mathematical model is required. For example, the slope of the size control curves shown in Figure $2 \mathrm{~B}$ is far from -1. Compared with the real situation, the negative correlation between the duration of the Start phase and the birth size of daughter or mother cells is too weak. Moreover, as observed in Figure 5B, the phase diagrams for cln 3 and WT cells show a hook-like tail, which is the relationship between the concentration of FarlT at the Reentry point and the arrest duration when the final concentration of pheromone is less than $15 \mathrm{nM}$. As shown in Figure 6A, when the duration of preexposure to pheromone is shorter than $15 \mathrm{~min}$, the Whi5threshold is volatile. These local non-monotonic kinetics in cell fate decision are worthy of further consideration. In addition, to verify the stability of the cellular transition, a stochastic model [19,30-32] is expected in our next research. Sensitivity analysis is also required because only one set of parameters is used in our model $[33,34]$.

\section{SUPPLEMENTARY MATERIALS}

The supplementary materials can be found online with this article at DOI 10.1007/s40484-015-0043-0.

\section{ACKNOWLEDGMENTS}

This work was supported by the Major Research Plan of the National Natural Science Foundation of China (No. 91230118 and No.91330113) and the National Natural Science Foundation of China (No.11275259 and No. 61173060). 


\section{COMPLIANCE WITH ETHICS GUIDELINES}

The authors Wenlong Li, Ming Yi, and Xiufen Zou declare that there is no conflict of interests.

This article does not contain any studies with human or animal subjects performed by any of the authors.

\section{APPENDIX A: SUBSYSTEM OF G1 CELL CYCLE}

$$
\begin{gathered}
\frac{\mathrm{d} V}{\mathrm{~d} t}=0.0063 V . \\
\frac{\mathrm{d}}{\mathrm{d} t}[C \ln 3]=k_{1} V-d_{1}[C \ln 3] . \\
\frac{\mathrm{d}}{\mathrm{d} t}[C \ln 1 / 2]= \\
k_{2}+\frac{k_{3}[S B F A]+k_{4}[M B F P]}{1+K_{3}[S B F A]+K_{4}[M B F P]} \\
-d_{2}[\text { Far } 1 P P][C \ln 1 / 2]-d_{3}[C \ln 1 / 2] .
\end{gathered}
$$

$$
\begin{aligned}
\frac{\mathrm{d}}{\mathrm{d} t}[S B F A]= & k_{5}[C \ln 3][S B F P]+k_{6}[C \ln 1 / 2][S B F P] \\
& +k_{7}\left[C l b 5 / 6_{\text {free }}\right][S B F P]-k_{8}[S B F A][\text { Whi5 }] .
\end{aligned}
$$

$$
[S B F P]=[S B F T]-[S B F A]
$$

$$
\begin{aligned}
\frac{\mathrm{d}}{\mathrm{d} t}[M B F P]= & k_{13}[C \ln 3][M B F]+k_{14}[C \ln 1 / 2][M B F] \\
& +k_{15}\left[C l b 5 / 6_{\text {free }}\right][M B F]-k_{16}[\text { Whis }][M B F P] .
\end{aligned}
$$

$$
\begin{aligned}
\frac{\mathrm{d}}{\mathrm{d} t}[\text { Whi5P }]= & k_{9}[C \ln 3][\text { Whi5 }]+k_{10}[C \ln 1 / 2][\text { Whi5 }] \\
& +k_{11}\left[C l b 5 / 6_{\text {free }}\right][\text { Whis }]-k_{12}[\text { Whi5P }]
\end{aligned}
$$

$$
[\text { Whi5] }=[\text { Whi5T }]-[\text { Whi5P }] \text {. }
$$

$$
[M B F]=[M B F T]-[M B F P] .
$$

$$
\begin{aligned}
\frac{\mathrm{d}}{\mathrm{d} t}[C l b 5 / 6]= & k_{17}+\frac{k_{18}[S B F A]+k_{19}[M B F P]}{1+K_{18}[S B F A]+K_{19}[M B F P]} \\
& -d_{4}[C l b 5 / 6] .
\end{aligned}
$$

$$
\begin{aligned}
\frac{\mathrm{d}}{\mathrm{d} t}[\operatorname{Sic} 1]= & k_{20}+\frac{k_{21}}{K_{21}+[C \ln 1 / 2]+\left[C l b 5 / 6_{\text {free }}\right]} \\
& -d_{6}([\operatorname{Sic} 1]-[\operatorname{Sic} 1 P])-d_{7}[\operatorname{Sic} 1 P] . \quad(\mathrm{A} 11)
\end{aligned}
$$

$$
\begin{aligned}
\frac{\mathrm{d}}{\mathrm{d} t}[C 5 S]= & b\left[C l b 5 / 6_{\text {free }}\right]\left[S i c 1_{\text {free }}\right] \\
& -\left(d_{8}+d_{4}+d_{6}\left(1-\frac{[S i c 1 P]}{[S i c 1]}\right)+d_{7} \frac{[S i c 1 P]}{[S i c 1]}\right)[C 5 S] . \\
\Lambda & =\lambda_{1}\left[C l b 5 / 6_{\text {free }}\right]+\lambda_{2}[C \ln 1 / 2] .
\end{aligned}
$$

$$
\begin{aligned}
\frac{\mathrm{d}}{\mathrm{d} t}[\operatorname{Sic} 1 P 1]= & \Lambda([\operatorname{Sic} 1]-[\operatorname{Sic} 1 P T]) \\
& +r[\operatorname{Sic} 1 P 2]-\left(\Lambda+r+d_{6}\right)[\operatorname{Sic} 1 P 1] .
\end{aligned}
$$

$$
\begin{aligned}
\frac{\mathrm{d}}{\mathrm{d} t}[\operatorname{Sic} 1 P i]= & \Lambda[\operatorname{Sic} 1 P(i-1)]+r[\operatorname{Sic} 1 P(i+1)] \\
& -\left(\Lambda+r+d_{6}\right)(\operatorname{Sic} 1 P i), i=2, \cdots, 5 .
\end{aligned}
$$

$$
\begin{aligned}
\frac{\mathrm{d}}{\mathrm{d} t}[\operatorname{Sic} 1 P i]= & \Lambda[\operatorname{Sic} 1 P(i-1)]+r[\operatorname{Sic} 1 P(i+1)] \\
& -\left(\Lambda+r+d_{7}\right)[\operatorname{Sic} 1 P i], i=6, \cdots, 8 .
\end{aligned}
$$

$$
\frac{\mathrm{d}}{\mathrm{d} t}[\operatorname{Sic} 1 P 9]=\Lambda[\operatorname{Sic} 1 P 8]-\left(r+d_{7}\right)[\operatorname{Sic} 1 P 9] .
$$

$$
\left[C l b 5 / 6_{\text {free }}\right]=[C l b 5 / 6]-[C 5 S]
$$

$$
[\operatorname{Sic} 1 P]=\sum_{i=6}^{9}[\operatorname{Sic} 1 P i]
$$

$$
[\operatorname{Sic} 1 P T]=\sum_{i=1}^{9}[\operatorname{Sic} 1 P i]
$$

$$
\left[S i c 1_{\text {free }}\right]=[S i c 1]-[C 5 S]
$$

$$
\begin{aligned}
\frac{\mathrm{d}}{\mathrm{d} t}[\text { Ste } 12]= & -\frac{k_{22}[\text { Fus } 3 P P][\text { Ste } 12]}{K_{22}+[\text { Ste } 12]} \\
& +k_{23}[\text { Ste } 12 P P] .
\end{aligned}
$$

$$
[\text { Ste } 12 P P]=[\text { Ste } 12 T]-[\text { Ste } 12] \text {. }
$$

$$
\frac{\mathrm{d}}{\mathrm{d} t}[\text { Far } 1]=k_{24}+\frac{k_{25}[\text { Ste } 12 P P]}{K_{25}+[\operatorname{Ste} 12 P P]}-d_{5}[\operatorname{Cln} 1 / 2]([\text { Far } 1]
$$

$$
-[\operatorname{Far} 1 P P])-d_{9}[\operatorname{Far} 1] \text {. }
$$




$$
\begin{aligned}
\frac{\mathrm{d}}{\mathrm{d} t}[\text { Far } 1 P P]= & k_{26}([\text { Far } 1]-[\text { Far } 1 P P])[\text { Fus } 3 P P] \\
& -k_{27}[\text { Far } 1 P P] .
\end{aligned}
$$

\section{APPENDIX B: SUBSYSTEM OF MATING PATHWAY}

$$
\begin{aligned}
& \frac{\mathrm{d}}{\mathrm{d} t}[S t e 2]=-\kappa_{1}[S t e 2] \alpha(t) \\
& \quad+\kappa_{2}\left[\text { Ste } 2_{\text {active }}\right]-\delta_{1}[S t e 2]
\end{aligned}
$$

$\frac{\mathrm{d}}{\mathrm{d} t}\left[\right.$ Ste $\left.2_{\text {active }}\right]=\kappa_{1}[$ Ste 2$] \alpha(t)-\kappa_{2}\left[\right.$ Ste $\left.2_{\text {active }}\right]-\delta_{2}\left[S t e 2_{\text {active }}\right]$.

$$
\begin{aligned}
\frac{\mathrm{d}}{\mathrm{d} t}[\text { Ste } 5 P 0]= & -8 \kappa_{3}[\text { Cln } 1 / 2][\text { Ste } 5 P 0]+\kappa_{3 r}[\text { Ste } 5 P 1] \\
& -\delta_{\text {ste } 0}[\text { Ste } 5 P 0]+\gamma_{0}\left[\text { Ste } 5 P 0_{\text {mem }}\right]
\end{aligned}
$$

$$
\begin{aligned}
\frac{\mathrm{d}}{\mathrm{d} t}[\text { Ste } 5 P i]= & (9-i) \kappa_{3}[\text { Cln } 1 / 2][\text { Ste } 5 P(i-1)] \\
& -i \kappa_{3 r}[\text { Ste } 5 P i]-(8-i) \kappa_{3}[\text { Cln } 1 / 2][\text { Ste } 5 P i] \\
& +(i+1) \kappa_{3 r}[\text { Ste } 5 P(i+1)]-\delta_{\text {stei }}[\text { Ste } 5 P i] \\
& +\gamma_{i}\left[\text { Ste } 5 P i_{\text {mem }}\right], i=1,2,3, \cdots, 7 .
\end{aligned}
$$

$$
\begin{gathered}
\frac{\mathrm{d}}{\mathrm{d} t}\left[\text { Ste5P8] }=\kappa_{3}[\text { Cln } 1 / 2][S t e 5 P 7]-8 \kappa_{3 r}[\text { Ste } 5 P 8]\right. \\
-\delta_{\text {ste }}[\text { Ste } 5 P 8]+\gamma_{8}\left[\text { Ste } 5 P 8_{\text {mem }}\right] .(\mathrm{B} 11) \\
\frac{\mathrm{d}}{\mathrm{d} t}\left[S t e 5 P i_{\text {mem }}\right]=\delta_{\text {stei }}[\text { Ste } 5 P i]-\gamma_{i}\left[S t e 5 P i_{\text {mem }}\right], i=0,1, \cdots 8 .
\end{gathered}
$$

$$
\begin{gathered}
{\left[\text { Ste }_{\text {total }}\right]=\sum_{i=0}^{8}\left([\text { Ste } 5 P i]+\left[S t e 5 P i_{\text {mem }}\right]\right) .} \\
{\left[S t e 5_{\text {mem }}\right]=\sum_{i=0}^{8}\left[S t e 5 P i_{\text {mem }}\right] .} \\
\frac{\mathrm{d}}{\mathrm{d} t}\left[G_{\beta \gamma}\right]=\kappa_{4}\left[S t e 2_{\text {active }}\right]\left[G_{\alpha \beta \gamma}\right] \\
+\kappa_{5}[D]-\kappa_{6}[C]\left[G_{\beta \gamma}\right] .
\end{gathered}
$$

$$
\frac{\mathrm{d}[A]}{\mathrm{d} t}=\kappa_{8}\left[\text { Ste } 5_{\text {total }}\right][\text { Ste } 11]-\kappa_{7}[A]-\kappa_{11}[A][B] .
$$

$$
\frac{\mathrm{d}[B]}{\mathrm{d} t}=\kappa_{10}[\text { Ste } 7][\text { Fus } 3]-\kappa_{9}[B]-\kappa_{11}[A][B] .
$$

$$
\frac{\mathrm{d}[C]}{\mathrm{d} t}=\kappa_{11}[A][B]+\kappa_{5}[D]-\kappa_{6}\left[G_{\beta \gamma}\right][C] .
$$

$$
\begin{aligned}
\frac{\mathrm{d}[D]}{\mathrm{d} t}= & -\kappa_{5}[D]+\kappa_{6}\left[G_{\beta \gamma}\right][C] \frac{\left[\text { Ste } 5_{\text {mem }}\right]}{\left[\text { Ste } 5_{\text {total }}\right]} \\
& -\kappa_{12}[\text { Ste } 20][D]+\kappa_{13}[E] .
\end{aligned}
$$

$$
\frac{\mathrm{d}[E]}{\mathrm{d} t}=\kappa_{12}\left[\text { Ste20][D]- } \kappa_{13}[E]-\kappa_{14}[E] .\right.
$$

$$
\frac{\mathrm{d}[F]}{\mathrm{d} t}=\kappa_{14}[E]-\kappa_{15}[F]
$$

$$
\frac{\mathrm{d}[G]}{\mathrm{d} t}=\kappa_{15}[F]-\kappa_{16}[G]
$$

$$
\frac{\mathrm{d}[H]}{\mathrm{d} t}=\kappa_{16}[G]-\kappa_{17}[H] .
$$

$$
\frac{\mathrm{d}[I]}{\mathrm{d} t}=\kappa_{17}[H]+\kappa_{18}[K]-\kappa_{21}[I]
$$

$$
\frac{\mathrm{d}[J]}{\mathrm{d} t}=\kappa_{21}[I]-\kappa_{19}[J][F u s 3]+\kappa_{20}[K]-\kappa_{23}[J] .
$$

$$
\frac{\mathrm{d}[K]}{\mathrm{d} t}=\kappa_{19}[J][F u s 3]-\kappa_{20}[K]-\kappa_{18}[K] .
$$

$$
\begin{aligned}
\frac{\mathrm{d}}{\mathrm{d} t}[\text { Fus } 3]= & \kappa_{9}[B]-\kappa_{10}[\text { Ste } 7][\text { Fus } 3]-\kappa_{19}[\text { Fus } 3][J] \\
& +\kappa_{20}[K]+\kappa_{22}[\text { Fus } 3 P P]
\end{aligned}
$$

$$
\frac{\mathrm{d}}{\mathrm{d} t}[F u s 3 P P]=-\kappa_{22}[F u s 3 P P]+\kappa_{21}[I] .
$$

\section{REFERENCES}

1. Furlong, E. E. (2010) The importance of being specified: cell fate decisions and their role in cell biology. Mol. Biol. Cell, 21, 3797-3798

2. Morgan, D. O. (2007) The cell cycle. London: New Science Press

3. Yang, L., MacLellan, W. R., Han, Z., Weiss, J. N. and Qu, Z. (2004) Multisite phosphorylation and network dynamics of cyclin-dependent kinase signaling in the eukaryotic cell cycle. Biophys. J., 86, 34323443

4. Bardwell, L., Zou, X., Nie, Q. and Komarova, N. L. (2007) Mathematical models of specificity in cell signaling. Biophys. J., 92, 3425-3441 
5. Zou, X., Peng, T. and Pan, Z. (2008) Modeling specificity in the yeast MAPK signaling networks. J. Theor. Biol., 250, 139-155

6. Kofahl, B. and Klipp, E. (2004) Modelling the dynamics of the yeast pheromone pathway. Yeast, 21, 831-850

7. Li, Y., Yi, M. and Zou, X. (2013) Identification of the molecular mechanisms for cell-fate selection in budding yeast through mathematical modeling. Biophys. J., 104, 2282-2294

8. Chang, F. and Herskowitz, I. (1990) Identification of a gene necessary for cell cycle arrest by a negative growth factor of yeast: FAR1 is an inhibitor of a G1 cyclin, CLN2. Cell, 63, 999-1011

9. McKinney, J. D., Chang, F., Heintz, N. and Cross, F. R. (1993) Negative regulation of FAR1 at the Start of the yeast cell cycle. Genes Dev., 7, 833-843

10. Yang, X., Lau, K. Y., Sevim, V. and Tang, C. (2013) Design principles of the yeast G1/S switch. PLoS Biol., 11, e1001673

11. Mangan, S. and Alon, U. (2003) Structure and function of the feedforward loop network motif. Proc. Natl. Acad. Sci. USA, 100, 11980 11985

12. Doncic, A. and Skotheim, J. M. (2013) Feedforward regulation ensures stability and rapid reversibility of a cellular state. Mol. Cell, 50, 856868

13. Doncic, A., Falleur-Fettig, M. and Skotheim, J. M. (2011) Distinct interactions select and maintain a specific cell fate. Mol. Cell, 43, 528539

14. Novak, B., Tyson, J. J., Gyorffy, B. and Csikasz-Nagy, A. (2007) Irreversible cell-cycle transitions are due to systems-level feedback. Nat. Cell Biol., 9, 724-728

15. Skotheim, J. M., Di Talia, S., Siggia, E. D. and Cross, F. R. (2008) Positive feedback of G1 cyclins ensures coherent cell cycle entry. Nature, 454, 291-296

16. Charvin, G., Oikonomou, C., Siggia, E. D. and Cross, F. R. (2010) Origin of irreversibility of cell cycle start in budding yeast. PLoS Biol., 8, e1000284

17. Hartwell, L. H., Culotti, J., Pringle, J. R. and Reid, B. J. (1974) Genetic control of the cell division cycle in yeast. Science, 183, 46-51

18. Cross, F. R. (1995) Starting the cell cycle: what's the point? Curr. Opin. Cell Biol., 7, 790-797

19. Talia, S. D., Skotheim, J. M., Bean, J. M., Siggia, E. D. and Cross, F. R. (2007) The effects of molecular noise and size control on variability in the budding yeast cell cycle. Nature, 448, 947-951

20. Di Talia, S., Wang, H., Skotheim, J. M., Rosebrock, A. P., Futcher, B. and Cross, F. R. (2009) Daughter-specific transcription factors regulate cell size control in budding yeast. PLoS Biol., 7, e1000221
21. Turner, J. J., Ewald, J. C. and Skotheim, J. M. (2012) Cell size control in yeast. Curr. Biol., 22, R350-R359

22. Hao, N., Nayak, S., Behar, M., Shanks, R. H., Nagiec, M. J., Errede, B., Hasty, J., Elston, T. C. and Dohlman, H. G. (2008) Regulation of cell signaling dynamics by the protein kinase-scaffold Ste5. Mol. Cell, 30, 649-656

23. Tyers, M. and Futcher, B. (1993) Far1 and Fus3 link the mating pheromone signal transduction pathway to three G1-phase Cdc28 kinase complexes. Mol. Cell. Biol., 13, 5659-5669

24. Takahashi, S. and Pryciak, P. M. (2008) Membrane localization of scaffold proteins promotes graded signaling in the yeast MAP kinase cascade. Curr. Biol., 18, 1184-1191

25. Hartwell, L. H. and Unger, M. W. (1977) Unequal division in Saccharomyces cerevisiae and its implications for the control of cell division. J. Cell Biol., 75, 422-435

26. Qu, Z., MacLellan, W. R. and Weiss, J. N. (2003) Dynamics of the cell cycle: checkpoints, sizers, and timers. Biophys. J., 85, 3600-3611

27. Colman-Lerner, A., Gordon, A., Serra, E., Chin, T., Orna, R., Endy, D., Pesce, C. G. and Brent, R. (2005) Regulated cell-to-cell variation in a cell-fate decision system. Nature, 437, 699-706

28. Paliwal, S., Iglesias, P. A., Campbell, K., Hilioti, Z., Groisman, A. and Levchenko, A. (2007) MAPK-mediated bimodal gene expression and adaptive gradient sensing in yeast. Nature, 446, 46-51

29. Yu, R. C., Pesce, C. G., Colman-Lerner, A., Lok, L., Pincus, D., Serra, E., Holl, M., Benjamin, K., Gordon, A. and Brent, R. (2008) Negative feedback that improves information transmission in yeast signalling. Nature, 456, 755-761

30. Ubersax, J. A. and Ferrell, J. E. (2006) A noisy 'Start' to the cell cycle. Mol. Syst. Biol., 2, 0014

31. Kar, S., Baumann, W. T., Paul, M. R. and Tyson, J. J. (2009) Exploring the roles of noise in the eukaryotic cell cycle. Proc. Natl. Acad. Sci. USA, 106, 6471-6476

32. Li Y. K., Yi M., Zou X. F. (2014) The linear interplay of intrinsic and extrinsic noises ensures a high accuracy of cell fate selection in budding yeast. Sci. Rep, 4, 5764

33. Zou, X., Xiang, X., Chen, Y., Peng, T., Luo, X. and Pan, Z. (2010) Understanding inhibition of viral proteins on type I IFN signaling pathways with modeling and optimization. J. Theor. Biol., 265, 691703

34. Sun, J., Yi, M., Yang, L., Wei, W., Ding, Y. and Jia, Y. (2014) Enhancement of tunability of MAPK cascade due to coexistence of processive and distributive phosphorylation mechanisms. Biophys. J., $106,1215-1226$ 